\begin{tabular}{|l|l|l|l|l|l|}
\hline J. Tek. Ling & Vol. 10 & No. 2 & Hal. 129 - 136 & Jakarta, Mei 2009 & ISSN 1441-318X \\
\hline
\end{tabular}

\title{
PENGETAHUAN LOKAL TENTANG LINGKUNGAN: STUDI KASUS ETNIS WAWONII, SULAWESI TENGGARA
}

\author{
Mulyati Rahayu, Mohammad Fathi Royyani dan Rugayah \\ Peneliti di Pusat Penelitian Biologi \\ Lembaga IImu Teknologi Lingkungan
}

\begin{abstract}
Wawonii ethnic represent the majority groups and ethnic origin dwelling Wawonii island, Southeast Sulawesi. In their traditional life, this ethnic has own manners and customs for managing natural resources. Local knowledge research's about environment ecosystem of owned Wawonii ethnic have been carried out since 2003 to 2006. Several countryside of Wawolaa, Lansilowo, Lampeapi, Bobolio and Dompo-dompo Jaya have been visited during this study. At least 6 kinds environment sets have been identified, manely "kura eya" primary forest, "lali bata" secondary forest, "anantalu" brushes, "laro wita" field, "laro le" grassland and "kapo" village. Although there local knowledge have a lot of change, however it still remain their wisdom and become the guidance in their daily activities.
\end{abstract}

Key words: Local knowledge, Wawonii ethnic, Southeast Sulawesi.

\section{PENDAHULUAN}

\subsection{Latar Belakang}

Indonesia merupakan Negara dengan tingkat keberagaman yang tinggi. Baik keberagaman hayati (biodiversity) maupun keberagaman tradisi (cultural diversity). Dari keberagaman tersebut memunculkan pengetahuan lokal dalam interaksinya dengan lingkungan. Pengetahuan lokal ini antara satu daerah dengan daerah lainnya berbeda, tergantung pada tradisi dan keanekaragaman hayati yang ada di daerah tersebut.

Pengetahuan lokal yang dimiliki masyarakat dalam hal lingkungan merupakan warisan tradisi hasil dari interaksi manusia dengan lingkungan. Pengetahuan lokal apabila digali dan dikembangkan bisa dijadikan acuan bagi manusia modern dalam menggelola alam secara berkelanjutan. Pengetahuan lokal yang dimiliki masyarakat bukan merupakan sesuatu yang ada dengan sendirinya, tetapi merupakan akumulasi dari pengalaman hidup dalam interaksinya dengan lingkungan dan pendukung kebudayaan lainnya. Dengan demikian pengetahuan yang dimiliki oleh masyarakat adalah dinamis, berubah, dan terbuka atas dialog-dialog dengan yang lainnya.

Dalam kedinamisan dan perubahan yang terjadi adakalanya pengetahuan yang dimiliki oleh masyarakat tidak cukup dapat beradaptasi. Banyak kasus memperlihatkan bahwa pengetahuan lokal masyarakat yang telah terbukti dapat mempertahankan kehidupan ternyata tidak sesuai dengan kondisi lingkungan yang telah terdegradasi. Perubahan pengetahuan dan tradisi juga bisa terjadi karena adanya arus modernisasi dan globalisasi. Turnbull ${ }^{11}$ mengemukakan bahwa adanya perubahan radikal di masyarakat akibat adanya pengaruh dari modernisasi dan globalisasi. 
Arus modernisasi dan globalisasi telah "memaksa" masyarakat untuk terlibat dalam interaksi secara bersama-sama dengan masyarakat global yang memiliki penguasaan teknologi dan keuangan yang jauh lebih baik. Bahkan menurut Sunito ${ }^{2)}$ kekuatan ekonomi dan sosial akan menghancurkan tatanan kelembagaan dan struktur sosial masyarakat lokal. Namun, perlu juga disadari bahwa setiap masyarakat lokal memiliki cara tersendiri dalam berinteraksi dan beradaptasi dengan suasana yang berubah. Mereka tetap memiliki cara dalam mengelola alam lingkungannya. Pengetahuan tentang alam dan fenomena alam, misalnya tetap menjadi panduan bagi masyarakat untuk melakukan aktifitas. Bagi masyarakat lokal, mengetahui fenomena alam merupakan suatu "keharusan" untuk meraih hasil yang maksimal. Tanpa pengetahuan tentang lingkungan dan fenomena alam, aktifitas mereka menjadi sia-sia tanpa makna. Pengetahuan tentang alam dan gejalanya, pada akhirnya melahirkan berbagai bentuk ritual tradisi yang berkaitan dengan aktifitas keseharian. Ritual tradisi tersebut merupakan aktifitas pembaharuan hubungan manusia dan alam lingkungan.

Pada dasarnya pemahaman terhadap lingkungan alam sekitarnya merupakan suatu upaya untuk mempertahankan hidup serta mengembangkan keturunannya. Seperti halnya masyarakat lokal lainnya di Indonesia, masyarakat Wawonii di Sulawesi Tenggara umumnya memiliki pemahaman dan pengetahuan lokal tentang lingkungan dengan baik yang ditunjukkan dengan pencirian setiap unit lingkungan yang ada disekitarnya. Pencirian setiap unit lingkungan tersebut didasarkan pada fungsi dan kenampakannya. Umumnya setiap unit lingkungan tersebut memiliki karakteristik yang menjadi cirri khas. Pengetahuan lokal ini, sebagai bentuk kearifan tradisional menurut Soedjito ${ }^{3)}$ cukup ilmiah dan rasional.

\subsection{Tujuan}

Pulau Wawonii yang terletak di jazirah tenggara propinsi Sulawesi Tenggara merupakan salah satu pulau kecil dan dihuni oleh etnis Wawonii. Keanekaragaman hayati dan pengetahuan local etnis ini belum pernah diteliti. Berkaitan dengan eratnya hubungan antara masyarakat Wawonii dengan sumberdaya alam dan lingkungannya maka perlu dilakukan penelitian pengungkapan pengetahuan local etnis ini sehingga dapat dijadikan dasar dalam pengelolaan yang berkelanjutan.

\section{METODE KERJA}

\subsection{Lokasi dan waktu penelitian}

Penelitian ini dilakukan di pulau Wawonii yang secara administratif masuk dalam Kabupaten Konawe, Propinsi Sulawesi Tenggara. Pulau ini dihuni oleh etnis Wawonii yang merupakan etnis asli dan kelompok masyarakat mayoritas, juga menjadi tempat tinggal dan mencari nafkah dari berbagai etnis lainnya seperti etnis Buton, Muna, Kulisusu, bahkan imigran dari Jawa dan Flores. Mayoritas penduduk pulau Wawonii beragama Islam, walaupun demikian mereka masih memegang kukuh pada tradisi dalam kesehariannya, seperti bercocok tanam, melaut, menentukan waktu hajatan dan sebagainya.

Penelitian ini dilakukan pada tahun 2003 - 2006, dalam beberapa kali kunjungan. Setiap kunjungan dilakukan selama 2 - 3 minggu. Lokasi penelitian adalah : desa Wawolaa, Lansilowo, Lampeapi, Bobolio dan Dompo-dompo Jaya (gambar 1). Dalam setiap kunjungan dilakukan evaluasi ulang data yang telah diperoleh sebelumnya. 


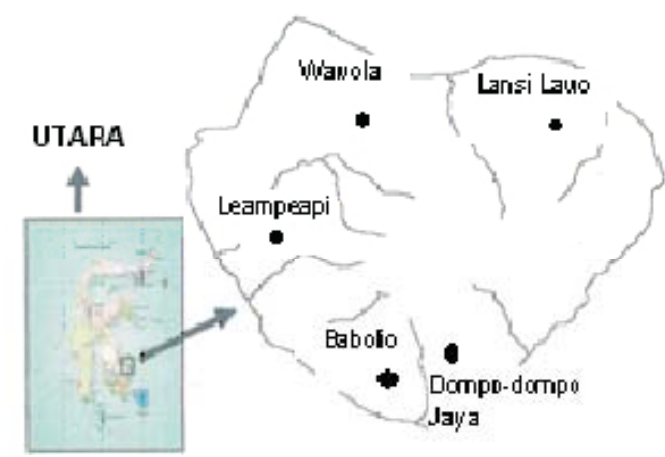

Gambar 1. Lokasi Penelitian

\subsection{Penentuan informan}

Dalam penelitian ini, dibedakan 2 kategori informan: yakni informan kunci dan informan biasa. Informan kunci terdiri dari tetua adat, dukun (sando), dan tokoh masyarakat dari tiap desa yang dikunjungi. Sedangkan informan biasa adalah masyarakat pulau Wawonii. Penentuan informan kunci maupun informan biasa berdasarkan teknik snowbolling, artinya informan tersebut didasarkan atas petunjuk dari informan sebelumnya. Setiap informan kunci harus paham mengenai budaya setempat.

\subsection{Strategi pengumpulan dan analisa data}

Penelitian ini merupakan penelitian etnobotani yang mengkaji pengetahuan dan persepsi masyarakat tentang lingkungan. Pengumpulan data dilakukan dengan cara wawancara secara "open ended", untuk mengungkap pengetahuan dan nama-nama lokal tentang lingkungan. Setelah satuan lingkungan diketahui maka dilanjutkan dengan wawancara secara mendalam, untuk mengungkap lebih dalam makna dari satuan lingkungan tersebut.

Pengungkapan maknasatuan lingkungan menjadi penting karena akan diketahui konsep masyarakat mengenai lingkungan. Data yang terkumpul kemudian dianalisa secara kualitatif. Proses pengumpulan data dan analisa dilakukan secara bersamaan, artinya ketika data telah diperoleh kemudian dianalisa untuk mengetahui hubungan makna satuan lingkungan dengan pengetahuan yang lainnya.

\section{HASIL DAN PEMBAHASAN}

\subsection{Masyarakat Wawonii dan satuan lingkungan}

Masyarakat pulau Wawonii umumnya bermata pencaharian sebagai petani atau peladang dan nelayan. Banyak juga diantara mereka yang berprofesi ganda, artinya ia sebagai nelayan juga memiliki ladang. Dalam melakukan aktifitasnya, masyarakat Wawonii masih berpegang pada tradisi turun temurun. Memulai perladangan, keinginan melaut, mengadakan hajatan, dan aktifitas harian lainnya masih berdasar tradisi, walaupun tidak bisa dipungkiri bahwa tradisi yang ada telah mengalami perubahan. Namun perubahan tersebut harus dipahami sebagai proses kreatif masyarakat untuk mempertahankan dirinya. Dengan sikap kreatif masyarakat maka tradisi yang dimiliki akan selalu mengalami pembaharuan, karena memang tradisi atau kebudayaan adalah sesuatu yang dinamis, bergerak, dan mengalami perubahan bukan sesuatu yang ajek dan statis. Bentuk satuan lingkungan yang dikenal oleh masyarakat Wawonii adalah sebagai berikut:

\subsubsection{Hutan rimba "kura eya" atau "laron kue"}

Pemahaman masyarakat Wawonii terhadap suatu lingkungan hutan rimba adalah kawasan hutan yang belum pernah terganggu/ditebang atau diusahakan sebagai kebun atau ladang. Kawasan hutan ini didalamnya ditumbuhi oleh berbagai tetumbuhan kayu yang berukuran besar dan tinggi, antara lain seperti "eha" Castanopsis buruana Miq., "kue mea" Palaquium obovatum (Griffith) Engl., "wowola" Calophyllum 
soulattri Burm. f., "humu mea" Santiria sp., "sisio" Podocarpus neriifolius D. Don, "kuma watu" Diospyros sp., dan "dongkala" Garcinia celebica L. Gangguan manusia dalam suatu lingkungan ini adalah eksploitasi kekayaan jenis tumbuhan terutama eksploitasi hasil kayunya. Sedangkan kerusakan akibat ekstrativisme hasil hutan seperti mengambil hasil buah-buahan antara lain Castanopsis buruana Miq., "dai" cempedak Artocarpus integer (Thunberg) Merrill, "ruruhi" dan "mogupa" Syzysium spp., "uwe" rotan Calamus spp. dan berburu dapat dikatakan tingkat kerusakannya relatif kecil dan tidak mempengaruhi klasifikasi lokal tentang satuan lingkungan "kura eya".

Hutan rimba bagi masyarakat Wawonii mempunyai peranan penting dalam kehidupan sehari-harinya, terutama dalam penyediaan bahan bangunan dan bahan pembuatan perahu. Kebutuhan bahan kayu untuk perahu selain untuk kebutuhan lokal (sendiri), juga untuk memenuhi pesanan dari luar pulau. Hal ini merupakan salah satu penyebab utama kerusakan hutan selain system pertanian ladang berpindah dan pembukaan lahan perkebunan "sokolati" coklat Theobroma cacao L., "nii" kelapa Cocos nucifera L., "dambo" jambu mete Anacardium occidentale L., dan "sengke" cengkeh Syzygium aromaticum (L.) Merrill dan Perry.

Kawasan hutan primer telah jarang ditemukan di pulau Wawonii, hanya dijumpai di kawasan lereng atau puncak pegunungan, antara lain pegunungan Waworete dan Lampeapi. Hal ini menjadi wajar karena jumlah pertambahan penduduk berjalan dengan cepat. Selain itu juga adanya anggapan di antara penduduk bahwa memperluas ladang, lebih menjamin kehidupan keluarga di masa depan daripada berilmu/ pendidikan sementara kontrol dari pemerintah tentang kepemilikan lahan sangat kurang bahkan bisa dikatakan tidak ada. Akibatnya, hutan-hutan primer menjadi berkurang dan ladang-ladang milik warga semakin merambah mendesak hutan.
Tumbuhan dan hutan, bagi masyarakat lokal pulau Wawonii tidak saja menyediakan berbagai kebutuhan, namun masyarakat juga beranggapan sebagai tempat bersemayamnya berbagai roh-roh makhluk halus. Dari kebutuhan dasar mereka seperti mencari bahan bangunan, mencari bahan makanan dan berburu sampai pada tujuan komersil untuk mencari keuntungan dapat terpenuhi. Di sisi lain kepercayaan terhadap roh untuk memenuhi kebutuhan sehari-hari dapat menjadi kontrol bagi masyarakat dalam membuka dan merambah hutan secara sembarangan.

Setiap memulai aktifitas interaksi dengan hutan, masyarakat terlebih dulu melakukan upacara untuk "membujuk" makhluk halus supaya tidak mengganggunya. Upacara ini selalu diikuti dengan memberikan sesajen I sesaji. Masyarakat meyakini bahwa pada tumbuhan tertentu bersemayam roh-roh yang apabila tumbuhan tersebut diganggu maka roh yang ada didalamnya akan menuntut balas. Apabila mereka terlanjur masuk hutan dan tanpa sengaja mengganggu roh yang ada didalamnya maka diadakan upacara "pembujukan". Masyarakat Wawonii percaya bahwa roh dapat mengganggu bahkan sampai membunuh individu orang atau keluarga bahkan masyarakat di suatu perkampungan.

\subsection{Hutan sekunder "lali bata"}

Satuan lingkungan yang dinamakan "lali bata" umumnya berupa hutan muda, bekas ladang yang ditinggalkan atau diberakan lebih dari 10 tahun. Keberadaan satuan lingkungan ini dapat dipastikan akibat adanya intervesi aktifitas manusia terhadap hutan primer. Intervensi ini dapat berupa eksploitasi hasil hutan yang berlebihan (penebangan pohon untuk pembuatan perahu) dan sistem pertanian tradisional ladang berpindah yang masih dianut oleh masyarakat Wawonii. Vegetasi yang mendominaasi hutan sekunder di pulau Wawonii a.I "arawa" Anthocephalus 
macrophyllus (Roxburgh) Havil., "bontu" waru Hibiscus tiliaceus L., "mata pute" Macaranga mappa (L.) Muel. Arg., dan "andolia" cempaka gunung Michelia champaca L.

Meningkatnya kebutuhan masyarakat akan Iahan untuk pertanian, ditambah dengan peningkatan jumlah penduduk dari factor kelahiran maupun migrasi dari pulau lain menyebabkan terjadinya pemendekan masa pemberaan. Pemendekan masa pemberaan membuat lahan bekas perladangan tidak benar-benar berubah menjadi hutan sekunder. Masyarakat Wawonii saat ini tidak lagi menganut pola perladangan berpindah melainkan telah memadukan dengan perkebunan. Lahan yang telah digunakan untuk tanaman musiman ketika masa tanamnya habis langsung ditanami oleh masyarakat dengan tanaman tahunan, sehingga hutan sekunder sudah jarang ditemukan di pulau Wawonii.

Konsep "lali bata" tidak berlaku pada hutan primer yang telah dieksploitasi manusia untuk produk timber dan non timber. Dari kawasan hutan sekunder ini, masyarakat mendapatkan berbagai macam kebutuhan hidupnya, seperti kayu bakar, binatang buruan, buah-buahan, dan lain-lain. Namun akibat adanya perubahan sistim perladangan membuat berbagai macam kebutuhan hidup yang awalnya mudah dijumpai kini sudah mulai sulit.

Perilaku masyarakat yang menanam lahan dengan tanaman tahunan memiliki motif tidak saja untuk peningkatan penghasilan melainkan juga sebagai usaha dan tanda penguasaan lahan, namun lahan yang telah ditanami dengan tanaman tahunan atau perkebunan banyak yang tidak terawat. Bahkan lahan tersebut menjadi semak belukar atau berubah menjadi "hutan" kembali atau dalam bahasa mereka menjadi anantalu.

\subsubsection{Semak belukar "anantalu"}

Pengertian kata "Anantalu" bagi etnis Wawonii adalah satuan lingkungan berupa bekas kebun yang telah ditinggalkan kurang dari 10 tahun. Kawasan ini umumnya didominasi oleh vegetasi "kateba" tapak liman Elephantopus scaber L., "rodu" Melastoma malabathricum D Don, "komba-komba" tembelekan Lantana camara L., "ewo bonto" babandotan Ageratum conyzoides L. dan "le" alang-alang Imperata cylindrica (L.) Beauv.

Pemilihan kawasan untuk dijadikan ladang pada setiap suku di Indonesia berbeda-beda. Pada suku Dayak di Kalimantan berdasarkan pada kemiringan dan kesuburan tanah dengan indikator warna tanah ${ }^{4}$, sedangkan pada suku Helong di pulau Semau, Nusa Tenggara Timur didasarkan pada pertumbuhan kanopi pada lahan yang akan digunakan sebagai ladang5). Satuan lingkungan anantalu dijadikan penciri oleh masyarakat dalam melakukan aktifitas pertanian. Masyarakat akan memulai aktifitas pertanian di anantalu bila vegetasi Elephantopus scaber dan Lantana camara telah mencapai tinggi 2-2,5 m umumnya lahan diolah kembali karena dianggap keadaan lahan telah subur kembali.

\subsubsection{Kebun campuran atau ladang "larowita"}

"Larowita" ladang atau kebun campuran merupakan tempat aktifitas utama masyarakat Wawonii di pulau Wawonii. Ladang awalnya merupakan sebidang tanah berasal dari hutan primer, hutan sekunder atau semak belukar dan diusahakan ditanami dengan tanaman pangan dan palawija. Penanaman padi ladang hanya dilakukan satu kali selama masa pengguna lahan dan penanaman hanya dilakukan pada lahan yang baru dibuka. Ini menunjukan pembukaan lahan baru terus berlangsung guna memenuhi kebutuhan pangan (beras) dan kemudian ditinggalkan atau ditanami dengan jenis tanaman palawija lainnya.

Jenis-jenis tanaman palawija yang diusahakan di kebun campuran a.l. "gandu" jagung Zea mays L., "pasikela keu" ubi kayu Manihot esculenta Crantz, "pasikela tou" ubi 
jalar Ipomoea batatas (L.) Lamk, "hoinu" okra Abelmoschus esculentus (L.) Moench, "palola" terung Solanum melongena L., "tomate" tomat S. lycopersicon L., "supere" labu kuning Cucurbita moschata (Duch ex Lamk) Duch., "ginta pae" cabai rawit Capsicum fructescens L., "mandola" Basella rubra L. dan lain-lain. Sedangkan jenis-jenis tanaman buah-buahan yang umum ditanam a.l. "punti" pisang Musa spp., "poo" mangga Mangifera spp., "lemo" jeruk Citrus spp., "kapaya" papaya Carica papaya L., dan nangka Artocarpus heterophyllus Lamk.

Menurut Dove ${ }^{6)}$ dan Ruthbenberg) strategi penanaman jenis-jenis seperti ini pada perladangan berpindah dijumpai hampir di seluruh masyarakat lokal di Asia Tenggara. Hal ini didukung oleh Brookfield \& Padoch $^{8)}$ yang menyatakan bahwa penanaman jenis-jenis tersebut pada system perladangan tidak memerlukan perawatan intensif dan teknologi yang berat.

Ladang biasanya dikelola selama 2-3 tahun, kemudian diberakan untuk mengembalikan kesuburan tanah atau ditanami dengan tanaman tahunan atau perkebunan. Model perladangan seperti ini sering dijumpai pada masyarakatmasyarakat tradisional di Indonesia. Perladangan model ini pada dasarnya memberikan kesempatan pada tanah untuk subur dan memangkas siklus hidup hama yang terdapat dalam tumbuhan tertentu. Hanya saja yang terjadi sangat ini masyarakat Wawonii telah mengalami perubahan yang drastis dalam sistem perladangan. Perubahan ini belum seluruhnya dapat diantisipasi oleh masyarakat, diantaranya belum adanya kesadaran bahwa hasil ladang yang mereka tanam untuk memenuhi kebutuhan pasar nasional dan global yang menuntut effisiensi, kontuinitas dan kualitas baik.

\subsubsection{Padang alang-alang "laro le"}

Persepsi masyarakat Wawonii terhadap bentuk satuan lingkungan "laro le" adalah hamparan kawasan pada dataran rendah yang didominasi oleh tumbuhan "le" alangalang Imperata cylindrica (L.) Beauv. Adanya padang alang-alang di pulau Wawonii merupakan akibat interaksi manusia terhadap alam sekitarnya terutama sistem perladangan berpindah. Keberadaan satuan lingkungan ini cukup luas terutama dijumpai di sekitar desa Bobolio dan Wawolaa. Pemanfaatan alang-alang sebagai salah satu bahan atap rumah seperti halnya di pulau Timor/Nusa Tenggara Timur ${ }^{9}$ tampaknya belum dikenal oleh masyarakat lokal di pulau Wawonii, namun akar tumbuhan ini telah dimanfaatkan sebagai bahan obat tradisional ${ }^{10)}$.

\subsubsection{Perkampungan atau pemukiman penduduk "kapo"}

Masyarakat Wawonii membentuk perkampungan atau pemukiman yang dikenal dalam bahasa lokal sebagai "kapo". Pemukiman di masa lalu terletak di daerah pegunungan, namun saat ini terletak pada tanah datar sekitar tepi pantai atau tepi sungai. Umumnya setiap keluarga memiliki "puturaha" pekarangan rumah seluas $25 x$ $50 \mathrm{~m}^{2}$ (Wawolaa dan Lampeapi) atau $20 \times 25$ $\mathrm{m}^{2}$ (Lansilowo, Bobolio dan Dompo-dompio Jaya), dengan luas bangunan rumah seluas 150 - $200 \mathrm{~m}^{2}$. Batas-batas pekarangan di desa Lansilowo, Wawolaa dan Bobolio tidak tampak jelas, hanya di bagian depan diberi pagar bambu dan dibagian dalamnya ditanami dengan tanamam kaca piring Gardeniajasminoides Ellis. Keanekaragaman jenis tanaman pekarangan tidak banyak dijumpai, umumnya lahan dibiarkan kosong diperuntukkan bagi penjemuran hasil panen jambu mete, coklat atau cengkeh.

Berbeda dengan ketiga desa tersebut di atas, batas-batas pekarangan di desa Lampeapi dan Dompo-dompo Jaya telah tampak jelas, bahkan pekarangan di desa Lampeapi meskipun dikelola secara sederhana dengan ditanami berbagai jenis tanaman, namun dapat menunjang penghasilan keluarga ${ }^{11)}$. 
Rumah asli masyarakat Wawonii berbentuk rumah panggung kayu disebut "raha malangga", beratap "bao" daun rumbia Metroxylon sagu Rottboel atau daun nipa Nypa fruticans Wurmb., dan berdinding "dopi" anyaman "tula" bambu. Bentuk rumah asli ini tidak mempunyai pembagian ruang dan "dapura" dapur terletak di luar bangunan rumah. Dapur merupakan tempat dimana masyarakat melakukan kegiatan memasak, menyimpan peralatan rumah tangga dan hasil panen untuk kebutuhan sehari-hari dalam rumah tangga.

Jalan-jalan desa yang terdapat di pulau Wawonii umumnya cukup lebar, antara 3-4 $\mathrm{m}$. Lebarnya jalan desa sering dimanfaatkan oleh masyarakat selain sebagai sarana infrastruktur yang menghubungkan antar wilayah, ruang terbuka untuk bermain atau melakukan interaksi dengan tetangga, juga digunakan untuk menjemur hasil panen ladang atau kebun seperti cengkeh, coklat, biji jambu mete dan lada.

\subsubsection{Bentuk satuan lingkungan lainnya}

a. Laut "tahi" merupakan hamparan air yang luas yang memisahkan 2 atau lebih "wawo" daratan atau pulau. Satuan lingkungan ini merupakan sumber utama mata pencaharian suku Bajo.

b. Sungai "lerolaa" merupakan aliran air yang cukup deras, berasal dari gunung dan merupakan sumber air untuk keperluan sehari-hari dan tempat untuk mencari ikan dan udang.

c. Gunung "wawono" yaitu kawasan yang mejulang tinggi, sulit untuk dijangkau dan udaranya dingin. Satuan lingkungan ini merupakan tempat tumbuhnya pohon-pohon besar yang di sebut juga "kuraeya".

\subsection{Masyarakat Wawonii dan kesatuan Kosmis}

Bagi masyarakat lokal pulau Wawonii, alam semesta dengan seluruh fenomena yang terkandung di dalamnya, serta kehadiran manusia di dalamnya, tidak saja melahirkan berbagai bentuk upacara tradisi melainkan juga melahirkan karakter berupa pandangan dan sikap hidup yang menghormati alam berupa sistem kepercayaan dan sistem nilai.

Kesatuan kosmis antara manusia dan alam merupakan bagian dari pembentuk kebudayaan. Pengetahuan tentang lingkungan yang terdapat pada masyarakat pulau Wawonii melahirkan pandangan dan kesadaran masyarakat tentang ruang dan waktu. Kesadaran tersebut pada akhirnya akan menjadi ritme hidup yang dilakoni masyarakat setiap hari, minggu, bulan, tahun, dan hitungan waktu lainnya. Ritme hidup yang berdasarkan kesadaran ini tidak saja telah dipraktekkan dalam sistem berladang dan aspek kehidupan lainnya melainkan juga terkandung harapanharapan masyarakat akan masa depan. Misalnya, di ruang alamiah seperti anantalu dapat dipakai sebagai isyarat bagi mereka untuk melakukan kapan melakukan suatu aktivitas yang berkaitan dengan matapencahariannya, dan hal tersebut menjadi pembatas aktivitas warga. Pemahaman tentang ruang (satuan lingkungan), waktu, gejala alam, dan lingkungan di selitarnya menjadi pedoman dalam beraktivitas bagi masyarakat lokal pulau Wawonii.

Harapan tentang kehidupan yang membaik terkait dengan ruang pada awalnya berhubungan dengan mata pencaharian, seperti dalam sistem pertanian, perladangan, berburu, dan pengambilan hasil hutan lainnya. Dari harapan dan aktivitas masyarakat terhadap pengetahuannya pada ruang, kemudian melahirkan berbagai upacara tradisi yang dilaksanakan sebagai ikhtiar menghindari kesialan dalam hidup mereka.

Ritual yang dilakukan oleh berbagai komunitas adat untuk memulai kembali musim tanam di sawah dan ladang bisa dilihat dari konteks seperti itu memperlihatkan hubungan antara manusia, alam, waktu, dan harapan-harapan, yang seluruhnya menjadi demikian sakral. Ritual merupakan "event" bagi masyarakat untuk menyegarkan kembali kepercayaan mereka yang dapat 
memberi identifikasi dan sugesti tentang sebuah kekuatan yang akan melindungi harapan-harapan manusia.

\section{KESIMPULAN}

Pengetahuan lokal etnis Wawonii, walaupun telah mengalami banyak perubahan dan juga memiliki keterbatasan, namun menyimpan kearifan antara lain berupa pengetahuan lokal tentang satuan lingkungan dan juga pemanfaatan tetumbuhan sebagai pemenuhan kebutuhan sehari-harinya.

Sebagai masyarakat yang "terbuka", pengetahuan yang dimiliki oleh etnis ini juga mengalami perubahan seiring dengan interaksi masyarakat dengan dunia luar. Perubahan pengetahuan ini merupakan keniscayaan karena pada dasarnya pengetahuan lokal juga merupakan hasil interaksi antara manusia dan alam, serta manusi dan manusia.

\section{DAFTAR PUSTAKA}

1. Turnbull, C.M. 2002.The Mbuti Pygmies: Changew and Adaptation. Wadworth. Thomson Learning 10 Davis Drive Belmont, CA, USA

2. Sunito, S. 2004. Robo and the Water Buffalo: The Lost Souls of Pekurehua of the Napu Valley. In: Gerhard, G., M. Fremerey, \& E. Guhardja (eds.). Land Use, Nature Conservation and Stability of Rainforest Margins in Southeast Asia. Springer.

3. Soedjito, H. \& E. Sukara. 2006. "Mengilmiahkan Pengetahuan Tradisional: Sumber IImu Masa Depan Indonesia", Dalam Kearifan Tradisional Cagar Biosfer di Indonesia. Prosiding Piagam MAB 2005 untuk Peneliti Muda dan Praktisi Lingkungan di Indonesia. Jakarta. Lembaga IImu Pengetahuan Indonesia dan Komite Nasional Man and the Biosphere.

4. Soedjito, H. 1995. Masyarakat Dayak: Perladangan dan Pelestarian Plas- ma Nutfah. Prosiding Seminar dan Lokakarya Nasional Etnobotani II : 330 - 341. 24-25 Januari 1995. Puslitbang Biologi-LIPI, Fak. Biologi UGM, Ikatan Pustakawan Indonesia, Yogyakarta.

5. Harahap, R. \& M.H. Siagian. 2000. Sistem Pertanian Berpindah Masyarakat Helong di Kecamatan Semau, Kabupaten Kupang, NTT. Prosiding Seminar Nasional Etnobotani III : 395 - 400. 5-6 Mei 1998. Puslitbang Biologi -LIPI, Univ. Udayana, Univ. Mahasaraswati. Denpasar, Bali.

6. Dove, M.R. 1988. Sistem Perladangan di Indonesia: Suatu Studi dari Kalimantan Barat. Gadjah Mada University Press, Yogyakarta.

7. Ruthernberg, H. 1980. Farming System in The Tropics. Clarendon Press, Oxford, England.

8. Brookfield, H.D. \& C. Padoch. 1994. Apreciating Agrodiversity: A Look at the Dynamism and Diversity of Indegineous Farming Practice. Environment 36 (5): 6-11, 37-44.

9. Rahayu, M., S. Susiarti \& M.H. Siagian. 1996. Etnobotani alang-alang Imperata cylindrica (L.) Beauv.: Pemanfaatannya dalam Kehidupan Sehari-hari bagi Masyarakat di Pulau Timor. Prosiding Seminar MIPA dalam Menunjang Pengembangan Industri dan Pengelolaan Lingkungan. 3 Desember 1996. Univ. Pakuan Bogor Hal : $52-54$.

10. Rahayu, M., S. Sunarti, D. Sulistiarini \& S. Prawiroatmodjo. 2006. Pemanfaatan Tumbuhan Obat Secara Tradisional oleh Masyarakat Lokal di Pulau Wawonii, Sulawesi Tenggara. Biodiversitas 7 (3): 245 -250.

11. Rahayu, M. \& S. Prawiroatmodjo. 2005. Keanekaragaman Tanaman Pekarangan dan Pemanfaatannya di Desa Lampeapi, Pulau Wawonii, Sulawesi Tenggara. Jurnal Teknologi Lingkungan 6 (2): 360 - 364. 